\title{
Overcoming Physiological Bottlenecks of Leaf Vitality and Root Development in Cuttings: A Systemic Perspective
}

\author{
Uwe Druege* \\ Erfurt Research Centre for Horticultural Crops (FGK), University of Applied Sciences Erfurt, Erfurt, Germany
}

Each year, billions of ornamental young plants are produced worldwide from cuttings that are harvested from stock plants and planted to form adventitious roots. Depending on the plant genotype, the maturation of the cutting, and the particular environment, which is complex and often involves intermediate storage of cuttings under dark conditions and shipping between different climate regions, induced senescence or abscission of leaves and insufficient root development can impair the success of propagation and the quality of generated young plants. Recent findings on the

OPEN ACCESS

Edited by:

Margherita Irene Beruto, Istituto Regionale per la Floricoltura

(IRF), Italy

Reviewed by:

Francisco Perez-Alfocea,

Spanish National Research Council,

Spain

Carmen Diaz-Sala,

University of Alcalá, Spain

*Correspondence:

Uwe Druege

uwe.druege@fh-erfurt.de

Specialty section:

This article was submitted to Crop and Product Physiology,

a section of the journal

Frontiers in Plant Science

Received: 24 April 2020

Accepted: 03 June 2020

Published: 30 June 2020

Citation:

Druege U (2020) Overcoming

Physiological Bottlenecks of Leaf

Vitality and Root Development

in Cuttings: A Systemic Perspective.

Front. Plant Sci. 11:907.

doi: 10.3389/fpls.2020.00907 molecular and physiological control of leaf vitality and adventitious root formation are integrated into a systemic perspective on improved physiologically-based control of cutting propagation. The homeostasis and signal transduction of the wound responsive plant hormones ethylene and jasmonic acid, of auxin, cytokinins and strigolactones, and the carbon-nitrogen source-sink balance in cuttings are considered as important processes that are both, highly responsive to environmental inputs and decisive for the development of cuttings. Important modules and bottlenecks of cutting function are identified. Critical environmental inputs at stock plant and cutting level are highlighted and physiological outputs that can be used as quality attributes to monitor the functional capacity of cuttings and as response parameters to optimize the cutting environment are discussed. Facing the great genetic diversity of ornamental crops, a physiologically targeted approach is proposed to define bottleneck-specific plant groups. Components from the field of machine learning may help to mathematically describe the complex environmental response of specific plant species.

Keywords: internal quality, senescence, adventitious rooting, plant development, phytohormones, primary metabolism, environment, modeling

\section{INTRODUCTION}

Plant propagation is the initial process of producing ornamental crops that already sets the first benchmark for the whole cultivation process by determining the quality of the young plant. Many ornamental plant species are propagated vegetatively by rooting of shoot tip cuttings. Depending on the plant genotype, the developmental stage of the cutting, and specific constellation of environmental factors, impaired vitality of cuttings or insufficient adventitious root (AR) formation in the stem base can cause leaf losses and dying of cuttings or failures in rooting 
and delayed or uneven root formation among individuals that impairs synchronous subsequent growth. Furthermore, the increasing demand on sustainability of young plant production requires improved propagation protocols that should provide maximum utilization of the genetically determined endogenous potential of the crop.

Propagation of ornamental plants by cuttings can be characterized as follows:

(1) It involves control of plant development in highly equipped ecosystems, that are mainly determined by technically controlled environmental inputs, for example in greenhouses, growth and storage rooms etc. I propose the term "technoecosystems" for such systems.

(2) Environmental inputs are highly dynamic, because propagation involves a complex chain of subsequent processes that occur in different environments. Stock plant cultivation and harvest of cuttings occurs in diverse climatic regions far remote from the market of young plants and is followed by packaging, storage, transport, sticking and cultivation of cuttings close to the market.

(3) The chain is continuously changing, because new priorities in the society and developing technologies provide new demands and options. Examples are the increasing demand for saving energy and reducing pollution, the changing lighting technology and the up-coming rooting systems that are compatible with transport logistics and sticking robots.

(4) There is a great genetic diversity of plants that are propagated by cuttings. This results from the high number of species used in floriculture and also from the high breeding activities bringing more than thousand new cultivars to the European market year by year. For example, in 2018, 140 applications for protection of Chrysanthemum varieties were submitted to the Community Plant Variety Office (Anonymus, 2019).

Considering this complex and highly dynamic situation, there is the need for a general concept, which helps to understand the limitation of and how to optimize cutting propagation in a specific system of interest, as characterized by the particular plant genotype and the environmental inputs that can be technically controlled during the specific chain. In this context, endogenous quality attributes of a cutting should reflect its current capacity to develop into a young plant. Recently, comprehensive review articles have provided detailed views on the molecular, hormonal and metabolic control of AR formation (Steffens and Rasmussen, 2016; Druege et al., 2019; Lakehal and Bellini, 2019). In this perspective article, the essential knowledge concerning this process is brought into context with the problem of leaf senescence and abscission, and further integrated into a systemic approach that faces the demands and the complex environment of ornamental horticulture. A physiologically based model of crucial processes determining the success in cutting propagation, their linkages to critical environmental inputs as well as those physiological outputs that can be used to monitor cutting function are introduced.

\section{SYSTEMIC MODEL OF PROPAGATION BY CUTTINGS}

\section{The Cutting Function}

The cutting is considered as functional unit in the center of the propagation system (Figure 1). Leaf retention and greenness and AR formation are the two targets of cutting function that determine the final quality of the young plant. Depending on the initial status of the AR source cells [cells, in which adventitious rooting starts (Druege et al., 2019)], their dedifferentiation may be involved first to gain competence for AR induction. Induction of AR competent cells leads to cell specification toward subsequent initiation (ending with the formation of primordia) and final expression of ARs from the stem base (SB). There, homeostasis of wound-responsive ethylene (ET) and jasmonic acid (JA), of the auxin indole-3-acetic acid (IAA), cytokinins (CK) and strigolactones (SL), and hormone signaling and function are core processes regulating AR formation, which is further dependent on sink establishment and $\mathrm{C}$ and $\mathrm{N}$ utilization. Fully developed leaves (FL) constitute important source tissues for $\mathrm{N}$ and $\mathrm{C}$ re-mobilization, while the developing leaves (DL) and shoot apex (SA) compete with the stem base (SB) for these resources. IAA accumulation in the $\mathrm{SB}$ is dependent on auxin re-mobilization from the upper shoot with polar auxin transport (PAT) as main driving process. The changed hormone homeostasis of the cutting may affect leaf senescence and abscission. Further explanation is given in Box 1.

\section{The Bottlenecks}

Depending on the plant genotype and configuration of environmental inputs at stock plant and cutting level, different processes may constitute the bottleneck (B) of cutting function (Figure 1).

\section{B1: General Auxin Responsiveness in the Stem Base}

If auxin signaling is generally low in the candidate AR source cells and not stimulated by the changed hormone homeostasis after cutting (see B2), no or few ARs will be formed. Cuttings, particularly of woody ornamentals such as Rosa or Hydrangea macrophylla, can exhibit low rooting capacity in dependence on the specific genotype (Dubois and Vries, 1991) or when they have been collected from mature parts of the stock plant (Galopin et al., 1996). The underlying principles are only fragmentary understood. A recent genome-wide association study of 95 rose genotypes indicated functions of the auxin and ET signal transduction (see also B2) in the diversity of AR formation, pointing to one auxin response factor (ARF), to cell fate regulating transcription factors (CTF), e.g., of the WOX- and GRAS-families that act down-stream of auxin, and to one positive regulator of the ET response pathway (Nguyen et al., 2020). In some forest tree species, the maturation-related decline in rooting capacity was related to divergences in expression of specific ARFs or CTF of the GRAS-family (Diaz-Sala, 2014, 2019). In Eucalyptus grandis, the maturation-induced decline in auxin-induced rooting was related to disturbed microtubule remodeling, which functional relevance was proven by chemical 


\section{Genotype}

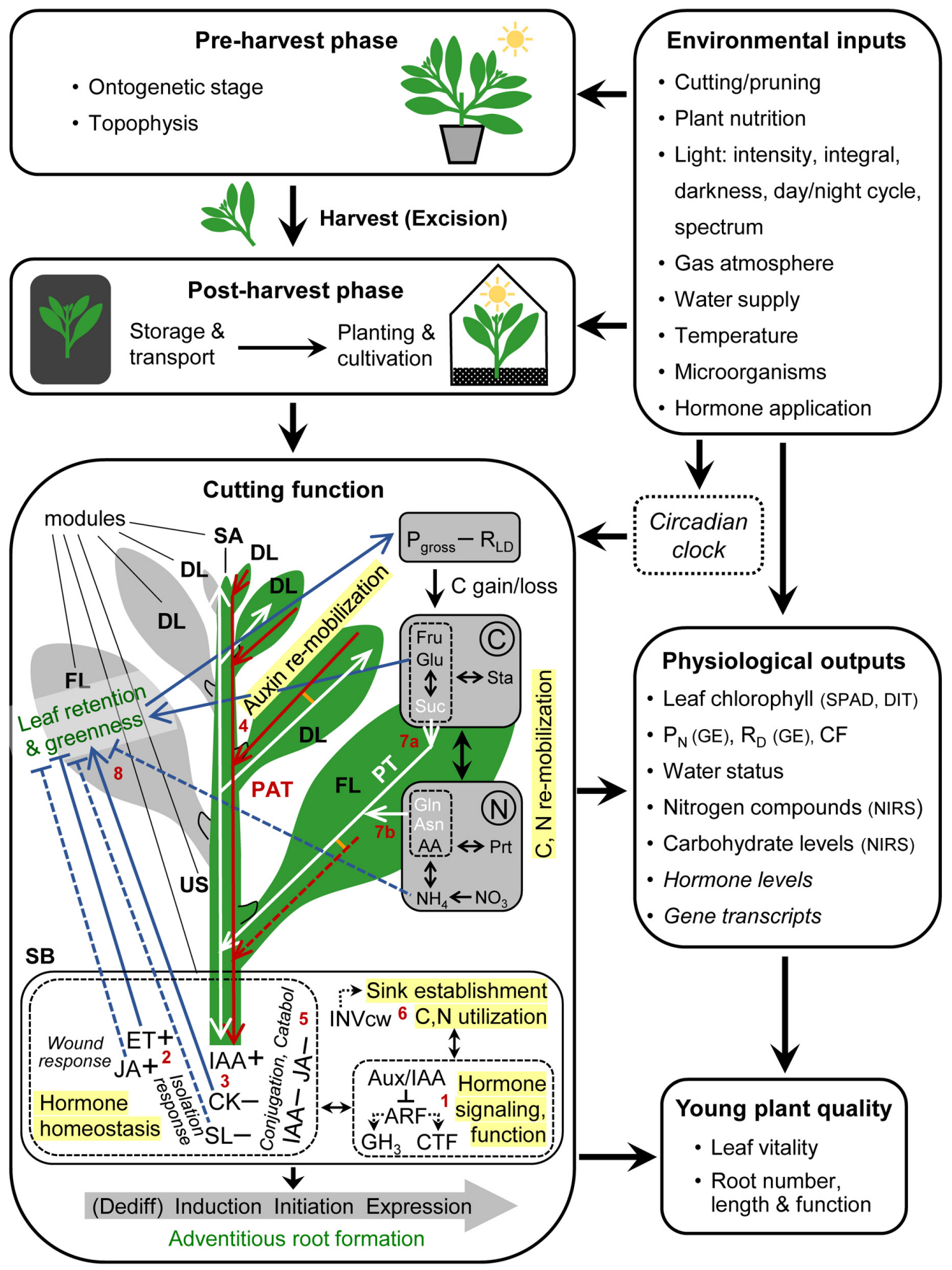

FIGURE 1 | Systemic, process-based model of clonal propagation by utilization of adventitious root formation in cuttings. Red and white lines and arrow heads indicate the pathways and directions of polar auxin transport (PAT) and phloem transport (PT), respectively. Lines in orange indicate PAT-PT connections. Blue lines ending with arrow heads or crossbars indicate positive or negative effects of increasing concentrations and of leaf retention and greenness, respectively. Plus versus minus signs indicate increased versus decrease of hormone concentrations, respectively, in response to excision. Red numbers indicate the bottlenecks explained in the text. Italic letters mark those physiological outputs, which are currently not accessible to routine analysis under practical conditions. Abbreviations between brackets indicate currently available measuring principles. AA, amino acids; ARF, auxin responsive factors; Aux/IAA, auxin/indole-3-acetic acid repressors; Asn, asparagine; CTF, cell fate regulating transcription factors; Catabol, catabolism; CK, cytokinins; Dediff, dedifferentiation; CF, chlorophyll fluorescence; DIT, digital image technology; DL, developing leaf; ET, ethylene; FL, fully developed leaf; GE, gas exchange analysis; GH3, Gretchen Hagen 3; Gln, glutamine; Glu, glucose; IAA, indole-3-acetic acid; INWcw, cell wall invertase; JA, jasmonic acid; NIRS, near infrared reflectance spectroscopy; $P_{N}$, net photosynthesis; $P_{\text {gross }}$, gross photosynthesis; Prt, proteins; $R_{D}$, dark respiration; $R_{L D}$, light and dark respiration; SA, shoot apex; SB, stem base; SL, strigolactones; SPAD, Soil Plant Analysis Development-chlorophyll meter; Sta, starch; suc, sucrose. Further explanations see Box $\mathbf{1}$ and the text. 
BOX 1| Targets, modules and processes of cutting function.

Leaf retention and greenness and adventitious root formation in the stem base are the two targets of cutting function that determine the final quality of the young plant, while physiological outputs can be used to monitor the cutting performance.

Plant genotype and environmental inputs, which act pre-harvest during the stock plant phase and after the harvest of cuttings, control the function of cuttings. This may also involve the circadian clock. The function of the cutting is further subject to the ontogenetic stage of the stock plant and to the cutting position within the stock plant (topophysis), which determines the specific developmental stage as well as the source-sink and hormonal status of the cutting tissues at time of harvest.

Important functional modules are the stem base (SB) as zone of root regeneration and of $\mathrm{C}$ and $\mathrm{N}$ utilization, the upper stem (US) as transport unit for all compounds and as intermediate storage unit of $\mathrm{C}$ and $\mathrm{N}$, the fully developed leaves (FL) as source organs for providing $\mathrm{C}$, $\mathrm{N}$ and possibly auxin, and the developing leaves (DL) and shoot apex (SA) as competitive utilization sinks for $C$ and $N$ and as potential source (DL) or sink (SA) of auxin.

In the SB, hormone homeostasis, signaling and function control the dedifferentiation (Dediff), induction, initiation and expression of adventitious roots, with Aux/IAA proteins, auxin responsive factor (ARF) transcription factors, GH3 proteins, and cell fate regulating transcription factors (CTF) such as GRAS, AP2/ERF and WOX as important components. Sink establishment and $\mathbf{C}$ and $\mathbf{N}$ utilization provide building blocks, energy and metabolic signals. Wound-induced accumulation of ethylene (ET) and jasmonic acid (JA), a decrease in levels of root-sourced cytokinins (CK) and strigolactones (SL) due to isolation from the stock plant, and accumulation of IAA contribute to dedifferentiation and induction of ARs. IAA accumulation in the stem base is dependent on auxin re-mobilization from the upper shoot, with DL and FL as potential auxin sources and polar auxin transport (PAT) as important process of translocation.

Depending on the sensitivity of the leaves, systemic effects of the changed plant hormone homeostasis may control leaf retention and greenness by affecting leaf senescence and abscission, with ethylene (ET) and cytokinins (CK) as classical trigger and inhibitors of leaf senescence or abscission, respectively. Whether the principally known agonistic effects of jasmonic acid (JA) and strigolactones (SL) on leaf senescence have relevance to cuttings, requires further investigation. High sugar levels, particularly of glucose can counteract leaf senescence/abscission, possibly via depressed ET signalling.

The earliness of establishment and the strength of the new utilization sink in the stem base as compared to the competing sink in the upper shoot limits the influx of $\mathrm{C}$ and $\mathrm{N}$ resources into the stem base. Activity of cell wall invertase (INVcW) as crucial driver of initial sink activity may be under positive control by IAA and JA $\mathbf{C}$ and $\mathbf{N}$ re-mobilization from the upper shoot, particularly from fully developed leaves is an important process for the delivery of sugars and amino acids (AA) to the utilization sink in the stem base, with sucrose (Suc), asparagine (Asn) and glutamine (Gin) as important components of phloem transport (PT).

The balance of gross photosynthesis ( $\left.\mathbf{P}_{\text {gross }}\right)$ and respiration in the light and in the dark $\left(R_{L D}\right)$ determines the carbon gain or loss of the leaf and thus its carbohydrate pool, with starch (Sta) and Suc as intermediate storage and main export fraction, respectively, while glucose (Glu) and Fructose (Fru) are locally utilized.

Light-dependent assimilation of nitrate and ammonium, that have been initially delivered from the root system of the stock plant, determines one influx of $\mathrm{N}$ into the AA and protein (Prt) pools, while competing with the sugar pool for $\mathrm{C}$ skeletons. Under prolonged dark conditions of whole cuttings that deplete the carbohydrate pool of leaves, leaf metabolism is readjusted towards a survival strategy, resulting in accumulation of AA, while proteolysis contributes to this process. If the released AAs are further catabolized to free ammonium, this may trigger leaf senescence.

manipulation (Abu-Abied et al., 2014). However, whether these relationships are based on bottleneck functions of the auxin signal transduction per se or rather reflect upstream limitations of cellular plasticity that is under further control of microRNAs and epigenetic factors (Poethig, 2013; Diaz-Sala, 2014; Druege et al., 2019) requires further investigation (see also B2).

\section{B2: Initial ET-JA-CK Interaction in the Stem Base}

If AR source cells require dedifferentiation before AR induction, early wound induced accumulation of ET and JA, together with CKs may contribute to this process by enhancing auxin responsiveness (Druege et al., 2019) (see B1).

\section{B3: Early Rise of Auxin/CK-SL Ratio in the Stem Base}

If AR source cells are root competent (see also B2), AR induction is dependent on local accumulation of IAA and further supported by a decrease in levels of the antagonistic CKs and SLs. Cutting off from (a) the root-ward auxin-drain and (b) the root-sourced delivery of CKs and SLs initiates these changes which may be supported by local IAA biosynthesis or release from auxin conjugates (Druege et al., 2019).

\section{B4: Auxin Re-mobilization From the Upper Shoot}

In intact plants, IAA is synthesized in young expanding leaves and is in the stem either transported root-ward by polar auxin transport (PAT) in xylem parenchyma and cambium cells or cotransported in the phloem associated with assimilate transport (AT) (Kramer and Bennett, 2006; Petrasek and Friml, 2009; Leyser, 2011; van Rongen et al., 2019), while in leaves both pathways can be interconnected (Cambridge and Morris, 1996; Figure 1). These auxin routes are supplemented with a low conductance and less polar "connective auxin transport," linking the PAT route to the surrounding tissues (Bennett et al., 2016; van Rongen et al., 2019). In shoot tip cuttings, PAT has important functions in auxin translocation toward the SB and, depending on the plant genotype and environmental condition, cutting leaves of different age may constitute important auxin sources (Guerrero et al., 1999; Garrido et al., 2002; Ahkami et al., 2013; Yang et al., 2019; Figure 1). Wounding and isolation of cuttings may trigger specific auxin biosynthetic pathways in addition to the pathways of the intact plant (Chen et al., 2016), possible via action of JA (Zhang et al., 2019).

\section{B5: Late Decrease in Auxin and JA Levels in the Stem Base}

Initiation and expression of ARs requires a decrease of IAA and probably also of the physiologically active conjugate of JA after the induction phase. Obviously, upregulation of specific GH3 proteins that function as acyl acid amido synthetases conjugating IAA or JA to specific AAs has an important role for this dynamic (Druege et al., 2019; Lakehal and Bellini, 2019). IAA level can be reduced also by catabolism, with oxidation as important route that can be triggered by JA (Lakehal et al., 2019; Figure 1).

\section{B6: Sink Establishment and C and N Utilization in the Stem Base}

Temporal courses of carbohydrates and amino acids (AA) in the stem base of cuttings during rooting (Ahkami et al., 2009) and the 
positive response of $\mathrm{AR}$ formation to applications of sugars and AA reveal that AR formation utilizes both resources (Orlikowska, 1992; Takahashi et al., 2003; Correa et al., 2005; Schwambach et al., 2005; Yasodha et al., 2008). After excision of cuttings, the transport route of these resources has to be directed toward the developing ARs, while the DLs and SA constitute competitive sink organs. Provided $\mathrm{C}$ or $\mathrm{N}$ sources are not the limiting factors (see B7), the strength of the new utilization sink in the SB limits the influx of $\mathrm{C}$ and $\mathrm{N}$ into the SB (Figure $\mathbf{1}$ and Box 1). This is determined by the activities of invertases, in particular cell wall invertase which can be up-regulated by IAA and JA (Roitsch and Gonzalez, 2004; Ahkami et al., 2009, 2013; Albacete et al., 2011; Agulló-Antón et al., 2014).

\section{B7: Surplus of $\mathrm{C}$ and $\mathrm{N}$ in Source Leaves}

If the sink in the SB is sufficiently high to attract resources (B6), their influx can be limited by the source capacity of the upper shoot, with the fully developed leaves (FL) as main source organs (Figure 1). Depending on the plant genotype and the particular environmental conditions during the chain, the magnitudes of either the $\mathrm{C}(B 7 a)$ or $\mathrm{N}$ source $(B 7 b)$ may limit rooting (Druege et al., 2000, 2004; Zerche et al., 2016). The available surplus of carbohydrates in cutting leaves depends on the initial carbohydrate level at time of planting and the current $\mathrm{C}$ gain during cutting cultivation (Rapaka et al., 2005), while current photosynthesis and $\mathrm{C}$ gain of cuttings is obviously dependent on plant species (Druege and Kadner, 2008; Klopotek et al., 2012). The level in leaves of total sugars, particularly of sucrose, during the rooting period reflects the carbohydrate source limitation of rooting in cuttings (Rapaka et al., 2005; Druege and Kadner, 2008; Klopotek et al., 2010).

\section{B8: Hormone Sensitivity of Leaves}

Senescence or abscission of leaves can impair the visual quality and vitality of cuttings and may finally cause decay and loss of whole cuttings. Changed concentrations in cuttings particularly of ET, JA, and CK in response to their excision have consequences for leaf senescence and/or abscission when the changed hormone homeostasis meets the respective responsiveness of the leaf (Figure 1 and Box 1). Both, the change in hormone levels and the leaf response are dependent on the plant genotype. Stimulation of ET biosynthesis by wounding or other stresses may promote leaf senescence in cuttings of sensitive plant species, particularly when packaging and storage of cuttings entraps the ET in the surrounding air (Müller et al., 1998; Rapaka et al., 2007a,b; Leatherwood et al., 2016). Depletion of CK in cuttings in response to the cut off from the root system can contribute to post-harvest leaf senescence, since CK application rescued leaf greenness antagonizing ET effects (Mutui et al., 2005). Observed agonistic effects of JA and SL on leaf senescence in intact plants (Ueda and Kusaba, 2015; Zhuo et al., 2020) may also be relevant to cuttings. Free ammonium can promote leaf senescence (Britto and Kronzucker, 2002), whereas high sugar levels obviously protect cutting leaves from senescence or abscission, while agonistic and antagonistic effects on ET signaling may be involved, respectively (Yanagisawa et al., 2003;
Druege et al., 2004; Rapaka et al., 2007a,b; Druege and Kadner, 2008; Li et al., 2019).

\section{Critical Environmental Inputs}

Diverse environmental factors at stock plant and cutting level modify the function of cuttings and thereby control the quality of the young plant as final output of the system (Figure 1). Mechanisms of plant nutritional factors and effects of controlled atmosphere storage are largely unexplored. In addition to the effects of light intensity and integral and of $\mathrm{CO}_{2}$ on the $\mathrm{C}$ gain of cuttings, distinct effects of light spectrum may involve changes of auxin homeostasis and signaling (Ruedell et al., 2015; Christiaens et al., 2019). Dark-induced carbohydrate depletion in cuttings can impair AR formation via reduced $\mathrm{C}$ source. However, if high photosynthetic activity of cuttings after the dark period allows fast recovery of the $\mathrm{C}$ source, dark storage can promote AR formation (Klopotek et al., 2010). In addition to the enhancement of AA levels in cuttings following carbohydrate depletion (Box 1), dark storage of cuttings may promote sink establishment in the stem base via up-regulation of invertases (Klopotek et al., 2016) and stimulate auxin signaling by enhanced auxin mobilization from the upper shoot (Yang et al., 2019). There is indication from growth analyses of petunia plants, that also the circadian clock, which coordinates plant metabolism with the environment, has important functions in carbon allocation toward roots (Feller et al., 2015). The mechanisms underlying the recently observed stimulation of AR formation by targeting of water to the rooting zone (sub-misting) when compared to overhead misting are not understood. There is indication that beneficial effects of inoculations of specific root endophytes, such as arbuscular mycorrhizal fungi or Serendipita indica (former Piriformospora indica) at stock plant or cutting level on leaf vitality and AR formation may involve changed $C$ source and hormone signaling in cuttings. However, effects of such inoculations are highly variable and even include negative effects on AR formation, when comparing different environmental conditions, modes of inoculation and plant genotype (Druege et al., 2006, 2007; Justice et al., 2018). This highlights the need for future research on the underlying mechanisms and key factors in the plant-microorganism-abiotic environment continuum. More details about the modes of action of the distinct environmental inputs (Figure 1) on cutting function consider also findings and concepts of Kadner and Druege (2004), Husen and Pal (2007), Rapaka et al. (2008), Bredmose and Nielsen (2009), AgullóAntón et al. (2011), Osterc and Stampar (2011), Franken (2012), da Costa et al. (2013), Bauerfeind et al. (2015), Rasmussen et al. (2015), Otiende et al. (2017), Zhang et al. (2017), Ferrari et al. (2018), Peterson et al. (2018), Taylor and Hoover (2018), Cho et al. (2019), Heide (2019), Sanchez et al. (2020) and are summarized in Supplementary Table S1.

\section{Physiological Outputs}

Distinct physiological parameters of cuttings can be used to monitor their function, which means to determine the efficiency of the processes contributing to leaf vitality and AR formation in the stem base (Figure 1). These parameters may be used to define the functional capacity of the cuttings as important internal 
quality attribute of cuttings or to adjust the environmental factors toward optimum cutting performance.

Even though the distinct effects of different levels and locations of water supply (top vs. bottom) on rooting of cuttings are unclear (Supplementary Table S1), monitoring the water status of cuttings can help to avoid water deficit induced limitation of leaf function (e.g., the reduction of carbon gain by stomatal closure) and AR formation at early rooting stages and to acclimate cuttings to moderate stress conditions at later rooting stages when ARs have already been formed. Water status of cuttings can be assessed by measuring transpiration viz. the water loss through the leaves, stomatal conductance representing the guard cell vapor conductivity, and the relative water content or water potential both reflecting the dehydration state of leaves or whole cuttings (Aminah et al., 1997; LeBude et al., 2005; Wilkerson et al., 2005). In addition to direct measurements of such parameters e.g., by use of gas exchange cuvettes, porometers etc., indirect methods and tools for real-time sensing of plant water status are increasingly available. These use for example stem thickness, leaf compressibility and thermal or spectral signatures of leaves (Millan-Almaraz et al., 2010; Steppe, 2015; Gerhards et al., 2019; Gautam and Pagay, 2020). However, the use of thermal signatures, which utilizes the dependency of leaf temperature on transpiration is complex in top-misting systems, where leaf temperature is decreased with each mist application.

Leaf chlorophyll content of leaves can be used to monitor leaf senescence and may also limit the $\mathrm{C}$ gain of cuttings by restriction of $\mathrm{P}_{\text {gross. }}$. One of the most frequently used non-invasive tools for chlorophyll analysis in plant leaves is the Soil Plant Analysis Development (SPAD) (Figure 1) chlorophyll meter (SPAD-502, Konica Minolta, Osaka, Japan), that measures leaf transmittance in the red $(650 \mathrm{~nm}$; the measuring wavelength) and infrared (940 $\mathrm{nm}$; a reference wavelength), while the output gives a relative value that is proportional to the chlorophyll content of the leaf (Ling et al., 2011). This tool has also been used in studies on ornamental crops, where nitrogen content as building block of chlorophyll was mostly the target (Bracke et al., 2019 and references therein) and also in some descriptive studies on cuttings (Rufai et al., 2016; Chater et al., 2017). Very high correlations can be found between chemically analyzed chlorophyll concentrations and SPAD values within a certain plant species as shown for Arabidopsis (Ling et al., 2011). However, the plant matrix obviously can affect these relationships as reflected by lower correlations, when ten different species of leafy vegetables were compared (Limantara et al., 2015). Digital image technology (DIT, Figure 1) is one alternative to analyze leaf color and also selectively chlorophyll contents, for example by use of the Red Green Blue color model. Such technologies may even provide a better estimation of chlorophyll than SPAD (Riccardi et al., 2014) and are further compatible to smartphones (Rigon et al., 2016).

Infrared gas analyzers can be used to determine the current carbon gain of cuttings or cutting leaves under the condition of measurement, which may, however, differ from the real conditions of rooting depending on the used measuring system (Druege and Kadner, 2008; Klopotek et al., 2012; Currey and Lopez, 2015; Tombesi et al., 2015). Use of chlorophyll fluorescence technology may provide information about the functional integrity of the photosynthetic apparatus. Quantum yield of PSII or quenching parameters in cutting leaves have already been used to determine their photosynthetic function as dependent on light acclimation (Rapaka et al., 2005), plant genotype (Druege and Kadner, 2008) and duration and temperature of dark storage (Faust and Enfield, 2010). Considering their relevance to the carbon gain and their stress response, online measurements of both leaf gas exchange and photosystem operating efficiency may be combined to optimize dynamic greenhouse control regimes during rooting of cuttings.

Considering that sugars and of AA in source tissues of cuttings reveal important fractions for the crucial $\mathrm{C}$ and $\mathrm{N}$ re-mobilization, analysis of their levels provides important information about the $\mathrm{C}$ and $\mathrm{N}$ source limitation of rooting (Druege et al., 2004; Rapaka et al., 2005; Zerche and Druege, 2009; Tombesi et al., 2015; Zerche et al., 2016). The N source availability in cuttings as affected by nitrogen fertilization of stock plants and by dark incubation is reflected not only by the levels of AA but also by the soluble organic nitrogen fraction (sum of amideand amino-N) (Zerche et al., 2019). Lohr et al. (2016, 2017) have recently established protocols for non-invasive quantification of (a) soluble nitrogen fractions and total nitrogen in cuttings and (b) total non-structural carbohydrates, starch and total sugars (sum of glucose+fructose+sucrose) in cutting leaves by use of near infrared reflectance spectroscopy (NIRS). These methods provide a new basis for the control of cutting quality as affected by their $\mathrm{C}$ and $\mathrm{N}$ source availability during the propagation chain. Considering the progress in NIRS measuring systems during recent years (Ishikawa et al., 2014) and the potential of hyperspectral imaging for detection of individual metabolites in plant tissues (Vergara-Diaz et al., 2020), more selective noninvasive monitoring of the cutting metabolome should become possible in future.

Since hormone levels in the cutting tissues have decisive functions in leaf senescence and AR formation, their analysis can discover important bottlenecks of cutting function. Whereas commercial systems are available to measure ET emission by plants in closed environments such as storage packages or boxes (Caprioli and Quercia, 2014; Tolentino et al., 2018), analysis of plant hormones in plant tissues requires cutting edge laboratory equipment (Novak et al., 2017) and highly skilled analysts. Polymerase chain reaction (PCR) is standard in detection of plant pathogens (Lau and Botella, 2017) and Reverse Transcriptase (RT) PCR is a frequently used tool in human medicine to detect the expression of critical genes, e.g., in cancer diagnosis (Sager et al., 2015). To my knowledge, up to date no RNA-based tools are available for routine determination of internal quality of plant products such as cuttings. Nevertheless, considering that environmentally and genetically mediated AR formation in cuttings can depend on plant hormones, especially of IAA or the transcript levels of signaling components such as ARF and GH3 genes (Ruedell et al., 2015; Yang et al., 2019), RNA-based quantitative diagnostic tools seem to have a high potential for next-generation functional diagnostics in cutting propagation. Considering the great diversity of ornamental plant species, such an approach must either be species-specific or focus on conserved 
DNA, respective RNA sequences that have same functions in several plant species.

\section{OUTLOOK}

The high complexity of highly dynamic environmental inputs in young plant production by cuttings and responding metabolic and hormonal pathways (Figure 1) is a challenge for the development of general rules or even mechanistic models to support a process-based management of cutting propagation. However, in a targeted approach the relevance of each potential bottleneck can be analyzed for selected plant species or cultivars and those can be grouped according to their identified bottlenecks. Further, the recently discussed concept of "plant perceptron" that implements components from the field of machine learning (Scheres and van der Putten, 2017) may help to mathematically describe these processes for model plant species. In such an approach, the early responding plant hormones JA, ET or IAA and the Aux/IAA-ARF modules (Figure 1) would constitute important environment-responsive factors of the so-called "top-hidden" and "bottom-hidden" layers of the information-processing system, respectively, that are weighted and integrated in the "output layer," where the transcription of genes that control cell division, expansion and fate is regulated (Scheres and van der Putten, 2017). Because the cutting function provides the core of the conception (Figure 1), the presented model is open for and may stimulate the use of new environmental inputs to control propagation by cuttings. Some of the discussed physiological outputs are currently utilizable only for researchers and experimental conditions, because their monitoring requires high technical input and very specific skills. However, we can expect that the continuous technological progress, e.g., in the application of molecular tools will open more possibilities in future for the propagation industry to utilize

\section{REFERENCES}

Abu-Abied, M., Szwerdszarf, D., Mordehaev, I., Yaniv, Y., Levinkron, S., Rubinstein, M., et al. (2014). Gene expression profiling in juvenile and mature cuttings of Eucalyptus grandis reveals the importance of microtubule remodeling during adventitious root formation. BMC Genomics 15:826. doi: 10.1186/1471-216415-826

Agulló-Antón, M. A., Ferrandez-Ayela, A., Fernandez-Garcia, N., Nicolas, C., Albacete, A., Perez-Alfocea, F., et al. (2014). Early steps of adventitious rooting: morphology, hormonal profiling and carbohydrate turnover in carnation stem cuttings. Physiol. Plant 150, 446-462. doi: 10.1111/ppl. 12114

Agulló-Antón, M. A., Sanchez-Bravo, J., Acosta, M., and Druege, U. (2011). Auxins or sugars: what makes the difference in the adventitious rooting of stored carnation cuttings? J. Plant Growth Regul. 30, 100-113. doi: 10.1007/s00344010-9174-8

Ahkami, A. H., Lischewski, S., Haensch, K.-T., Porfirova, S., Hofmann, J., Rolletschek, H., et al. (2009). Molecular physiology of adventitious root formation in Petunia hybrida cuttings: involvement of wound response and primary metabolism. New Phytol. 181, 613-625. doi: 10.1111/j.1469-8137.2008. 02704.x

Ahkami, A. H., Melzer, M., Ghaffari, M. R., Pollmann, S., Javid, M. G., Shahinnia, F., et al. (2013). Distribution of indole-3-acetic acid in Petunia hybrida shoot tip cuttings and relationship between auxin transport, carbohydrate metabolism physiological and molecular outputs of cuttings for optimizing the young plant production chain. Nevertheless, there will be the challenge to compromise between the specificity of targets, which increases with zooming from the crop to individual cuttings to individual organs such as FL or $\mathrm{SB}$, and the relevance to the whole crop.

\section{DATA AVAILABILITY STATEMENT}

All datasets generated for this study are included in the article/Supplementary Material, further inquiries can be directed to the corresponding author.

\section{AUTHOR CONTRIBUTIONS}

UD wrote the article.

\section{FUNDING}

This work was funded by the German Federal Ministry of Food and Agriculture (BMEL) based on a decision of the Parliament of the Federal Republic of Germany, granted by the Federal Office for Agriculture and Food (BLE; grant no. 2818HSE02).

\section{SUPPLEMENTARY MATERIAL}

The Supplementary Material for this article can be found online at: https://www.frontiersin.org/articles/10.3389/fpls.2020.00907/ full\#supplementary-material

TABLE S1 | Modes of action of environmental inputs on cutting function.

and adventitious root formation. Planta 238, 499-517. doi: 10.1007/s00425013-1907-z

Albacete, A., Grosskinsky, D. K., and Roitsch, T. (2011). Trick and treat: a review on the function and regulation of plant invertases in the abiotic stress response. Phyton 50, 181-204.

Aminah, H., Dick, J. M., and Grace, J. (1997). Influence of irradiance on water relations and carbon flux during rooting of Shorea leprosula leafy stem cuttings. Tree Physiol. 17, 445-452. doi: 10.1093/treephys/17.7.445

Anonymus (2019). CPVO Annual Report 2018. Luxembourg: Publications Office of the European Union.

Bauerfeind, M. A., Winkelmann, T., Franken, P., and Druege, U. (2015). Transcriptome, carbohydrate, and phytohormone analysis of Petunia hybrida reveals a complex disturbance of plant functional integrity under mild chilling stress. Front. Plant Sci. 6:583. doi: 10.3389/fpls.2015.00583

Bennett, T., Hines, G., van Rongen, M., Waldie, T., Sawchuk, M. G., Scarpella, E., et al. (2016). Connective auxin transport in the shoot facilitates communication between shoot apices. PLoS Biol. 14:e1002446. doi: 10.1371/journal.pbio. 1002446

Bracke, J., Eisen, A., Adriaenssens, S., Vandendriessche, H., and van Labeke, M. C. (2019). Utility of proximal plant sensors to support nitrogen fertilization in Chrysanthemum. Sci. Hortic. 256:108544. doi: 10.1016/j.scienta.2019. 108544

Bredmose, N. B., and Nielsen, K. L. (2009). Controlled atmosphere storage at high $\mathrm{CO}_{2}$ and low $\mathrm{O}_{2}$ levels affects stomatal conductance and influence root 
formation in kalanchoe cuttings. Sci. Hortic. 122, 91-95. doi: 10.1016/j.scienta. 2009.03.017

Britto, D. T., and Kronzucker, H. J. (2002). NH4+ toxicity in higher plants: a critical review. J. Plant Physiol. 159, 567-584. doi: 10.1078/0176-1617-0774

Cambridge, A. P., and Morris, D. A. (1996). Transfer of exogenous auxin from the phloem to the polar auxin transport pathway in pea (Pisum sativum L). Planta 199, 583-588.

Caprioli, F., and Quercia, L. (2014). Ethylene detection methods in post-harvest technology: a review. Sensor Actuat. B Chem. 203, 187-196. doi: 10.1016/j.snb. 2014.06.109

Chater, J. M., Merhaut, D. J., Preece, J. E., and Blythe, E. K. (2017). Rooting and vegetative growth of hardwood cuttings of 12 pomegranate (Punica granatum L) cultivars. Sci. Hortic. 221, 68-72. doi: 10.1016/j.scienta.2017.04.025

Chen, L. Q., Tong, J. H., Xiao, L. T., Ruan, Y., Liu, J. C., Zeng, M. H., et al. (2016). YUCCA-mediated auxin biogenesis is required for cell fate transition occurring during de novo root organogenesis in Arabidopsis. J. Exp. Bot. 67, 4273-4284. doi: $10.1093 /$ jxb/erw213

Cho, K. H., Laux, V. Y., Wallace-Springer, N., Clark, D. G., Folta, K. M., and Colquhoun, T. A. (2019). Effects of light quality on vegetative cutting and in vitro propagation of Coleus (Plectranthus scutellarioides). Hortscience 54, 926-935. doi: 10.21273/Hortsci13903-19

Christiaens, A., Gobin, B., van Huylenbroeck, J., and van Labeke, M. C. (2019). Adventitious rooting of Chrysanthemum is stimulated by a low red: far-red ratio. J. Plant Physiol. 236, 117-123. doi: 10.1016/j.jplph.2019.03.008

Correa, L. D., Paim, D. C., Schwambach, J., and Fett-Neto, A. (2005). Carbohydrates as regulatory factors on the rooting of Eucalyptus saligna Smith and Eucalyptus globulus labill. Plant Growth Regul. 45, 63-73. doi: 10.1007/ s10725-004-6125-z

Currey, C. J., and Lopez, R. G. (2015). Biomass accumulation and allocation, photosynthesis, and carbohydrate status of New Guinea impatiens, geranium, and petunia cuttings are affected by photosynthetic daily light integral during root development. J. Am. Soc. Hortic. Sci. 140, 542-549. doi: 10.21273/jashs. 140.6.542

da Costa, C. T., Almeida, M. R., de Ruedell, C. M., Schwambach, J., Maraschin, F. S., and Fett-Neto, A. G. (2013). When stress and development go hand in hand. Front. Plant Sci. 4:133. doi: 10.3389/fpls.2013.00133

Diaz-Sala, C. (2014). Direct reprogramming of adult somatic cells toward adventitious root formation in forest tree species. Front. Plant Sci. 5:310. doi: $10.3389 /$ fpls.2014.00310

Diaz-Sala, C. (2019). Molecular dissection of the regenerative capacity of forest tree species: special focus on conifers. Front. Plant Sci. 9:1943. doi: 10.3389/fpls. 2018.01943

Druege, U., Baltruschat, H., and Franken, P. (2007). Piriformospora indica promotes adventitious root formation in cuttings. Sci. Hortic. 112, 422-426. doi: 10.1016/j.scienta.2007.01.018

Druege, U., Hilo, A., Perez-Perez, J. M., Klopotek, Y., Acosta, M., Shahinnia, F., et al. (2019). Molecular and physiological control of adventitious rooting in cuttings: phytohormone action meets resource allocation. Ann. Bot. 123, 929-949. doi: 10.1093/aob/mcy234

Druege, U., and Kadner, R. (2008). Response of post-storage carbohydrate levels in pelargonium cuttings to reduced air temperature during rooting and the relationship with leaf senescence and adventitious root formation. Postharv. Biol. Technol. 47, 126-135. doi: 10.1016/j.postharvbio.2007. 06.008

Druege, U., Xylaender, M., Zerche, S., and Alten, H. (2006). Rooting and vitality of poinsettia cuttings was increased by Arbuscular mycorrhiza in the donor plants. Mycorrhiza 17, 67-72. doi: 10.1007/s00572-006-0074-5

Druege, U., Zerche, S., and Kadner, R. (2004). Nitrogen- and storage-affected carbohydrate partitioning in high-light-adapted Pelargonium cuttings in relation to survival and adventitious root formation under low light. Ann. Bot. 94, 831-842. doi: 10.1093/aob/mch210

Druege, U., Zerche, S., Kadner, R., and Ernst, M. (2000). Relation between nitrogen status, carbohydrate distribution and subsequent rooting of chrysanthemum cuttings as affected by pre-harvest nitrogen supply and cold-storage. Ann. Bot. 85, 687-701. doi: 10.1006/anbo.2000.1132

Dubois, L. A. M., and Vries, D. P. (1991). Variation in adventitious root formation of softwood cuttings of Rosa chinensis minima (Sims) Voss cultivars. Sci. Hortic. 47, 345-349. doi: 10.1016/0304-4238(91)90018-t
Faust, J. E., and Enfield, A. L. (2010). Effect of temperature and storage duration on quality and rooting performance of poinsettia (Euphorbia pulcherrima 'Prestige Red') cuttings. Acta Hortic. 877, 1799-1807. doi: 10.17660/actahortic.2010.877. 247

Feller, C., Favre, P., Janka, A., Zeeman, S. C., Gabriel, J. P., and Reinhardt, D. (2015). Mathematical modeling of the dynamics of shoot-root interactions and resource partitioning in plant growth. PLoS One 10:e0127905. doi: 10.1371/journal.pone. 0127905

Ferrari, A., Hagedorn, F., and Niklaus, P. A. (2018). Disentangling effects of air and soil temperature on $\mathrm{C}$ allocation in cold environments: a C-14 pulse-labelling study with two plant species. Ecol. Evol. 8, 7778-7789. doi: 10.1002/ece3. 4215

Franken, P. (2012). The plant strengthening root endophyte Piriformospora indica: potential application and the biology behind. Appl. Microbiol. Biotech. 96, 1455-1464. doi: 10.1007/s00253-012-4506-1

Galopin, G., Beaujard, F., and Gendraud, M. (1996). Intensive production of juvenile cuttings by mother microplant culture in Hydrangea macrophylla "Leuchtfeuer". Can. J. Bot. 74, 561-567. doi: 10.1139/b96-071

Garrido, G., Guerrero, J. R., Cano, E. A., Acosta, M., and Sanchez-Bravo, J. (2002). Origin and basipetal transport of the IAA responsible for rooting of carnation cuttings. Physiol. Plant 114, 303-312. doi: 10.1034/j.1399-3054.2002.1140217.x

Gautam, D., and Pagay, V. (2020). A review of current and potential applications of remote sensing to study the water status of horticultural crops. Agronomy 10:140. doi: 10.3390/agronomy10010140

Gerhards, M., Schlerf, M., Mallick, K., and Udelhoven, T. (2019). Challenges and future perspectives of multi-/hyperspectral thermal infrared remote sensing for crop water-stress detection. Remote Sens. 11:1240. doi: 10.3390/rs11101240

Guerrero, J. R., Garrido, G., Acosta, M., and Sanchez-Bravo, J. (1999). Influence of 2,3,5-triiodobenzoic acid and 1-N-naphthylphthalamic acid on indoleacetic acid transport in carnation cuttings: relationship with rooting. J. Plant Growth Regul. 18, 183-190. doi: 10.1007/Pl00007068

Heide, O. M. (2019). Juvenility, maturation and rejuvenation in plants: adventitious bud formation as a novel rejuvenation process. J. Hortic. Sci. Biotech. 94, 2-11. doi: 10.1080/14620316.2018.1482795

Husen, A., and Pal, M. (2007). Effect of branch position and auxin treatment on clonal propagation of Tectona grandis Linn. f. New Forest 34, 223-233. doi: 10.1007/s11056-007-9050-y

Ishikawa, D., Shinzawa, H., Genkawa, T., Kazarian, S. G., and Ozaki, Y. (2014). Recent progress of near-infrared (NIR) imaging -development of novel instruments and their applicability for practical situations. Anal. Sci. 30, 143150. doi: 10.2116/analsci.30.143

Justice, A. H., Faust, J. E., and Kerrigan, J. L. (2018). Evaluating a novel method to introduce a mycorrhizal-like fungus, Piriformospora indica, via an inoculated rooting substrate to improve adventitious root formation. Horttechnology 28, 149-153. doi: 10.21273/Horttech03914-17

Kadner, R., and Druege, U. (2004). Role of ethylene action in ethylene production and poststorage leaf senescence and survival of pelargonium cuttings. Plant Growth Regul. 43, 187-196. doi: 10.1023/b:grow.0000045999.61765.7e

Klopotek, Y., Franken, P., Klaering, H. P., Fischer, K., Hause, B., Hajirezaei, M. R., et al. (2016). A higher sink competitiveness of the rooting zone and invertases are involved in dark stimulation of adventitious root formation in Petunia hybrida cuttings. Plant Sci. 243, 10-22. doi: 10.1016/j.plantsci.2015. 11.001

Klopotek, Y., George, E., Druege, U., and Klaering, H.-P. (2012). Carbon assimilation of petunia cuttings in a non-disturbed rooting environment: response to environmental key factors and adventitious root formation. Sci. Hortic. 145, 118-126. doi: 10.1016/j.scienta.2012.08.004

Klopotek, Y., Haensch, K.-T., Hause, B., Hajirezaei, M.-R., and Druege, U. (2010). Dark exposure of petunia cuttings strongly improves adventitious root formation and enhances carbohydrate availability during rooting in the light. J. Plant Physiol. 167, 547-554. doi: 10.1016/j.jplph.2009.11.008

Kramer, E. M., and Bennett, M. J. (2006). Auxin transport: a field in flux. Trends Plant Sci. 11, 382-386. doi: 10.1016/j.tplants.2006.06.002

Lakehal, A., and Bellini, C. (2019). Control of adventitious root formation: insights into synergistic and antagonistic hormonal interactions. Physiol. Plant 165, 90-100. doi: 10.1111/ppl.12823

Lakehal, A., Dob, A., Novák, O., and Bellini, C. (2019). DAO1-mediated circuit controls auxin and jasmonate crosstalk robustness during adventitious root 
initiation in Arabidopsis. Int. J. Mol. Sci. 20:4428. doi: 10.3390/ijms201 84428

Lau, H. Y., and Botella, J. R. (2017). Advanced DNA-based point-of-care diagnostic methods for plant diseases detection. Front. Plant Sci. 8, 2016. doi: 10.3389/fpls. 2017.02016

Leatherwood, W. R., Dole, J. M., Bergmann, B. A., and Faust, J. E. (2016). 1-methylcyclopropene improves ethylene tolerance of unrooted herbaceous cuttings but delays adventitious root development in Angelonia, Calibrachoa, Impatiens, Portulaca, Sutera, and Verbena cultivars. Hortscience 51, 164-170. doi: 10.21273/hortsci.51.2.164

LeBude, A. V., Goldfarb, B., Blazich, F. A., Frampton, J., and Wise, F. C. (2005). Mist level influences vapor pressure deficit and gas exchange during rooting of juvenile stem cuttings of loblolly pine. Hortscience 40, 1448-1456. doi: 10 . 21273/Hortsci.40.5.1448

Leyser, O. (2011). Auxin, self-organisation, and the colonial nature of plants. Curr. Biol. 21, R331-R337. doi: 10.1016/j.cub.2011.02.031

Li, G. J., Zhang, L., Wang, M., Di, D. W., Kronzucker, H. J., and Shi, W. M. (2019). The Arabidopsis AMOT1/EIN3 gene plays an important role in the amelioration of ammonium toxicity. J. Exp. Bot. 70, 1375-1388. doi: 10.1093/jxb/ery457

Limantara, L., Dettling, M., Indrawati, R., Hardo, T., and Brotosudarmo, T. H. P. (2015). Analysis on the chlorophyll content of commercial green leafy vegetables. Proc. Chem. 14, 225-231. doi: 10.1016/j.proche.2015.03.032

Ling, Q. H., Huang, W. H., and Jarvis, P. (2011). Use of a SPAD-502 meter to measure leaf chlorophyll concentration in Arabidopsis thaliana. Photosynth. Res. 107, 209-214. doi: 10.1007/s11120-010-9606-0

Lohr, D., Tillmann, P., Druege, U., Zerche, S., Rath, T., and Meinken, E. (2017). Non-destructive determination of carbohydrate reserves in leaves of ornamental cuttings by near-infrared spectroscopy (NIRS) as a key indicator for quality assessments. Biosyst. Engin. 158, 51-63. doi: 10.1016/j.biosystemseng. 2017.03.005

Lohr, D., Tillmann, P., Zerche, S., Druege, U., Rath, T., and Meinken, E. (2016). Non-destructive measurement of nitrogen status of leafy ornamental cuttings by near infrared reflectance spectroscopy (NIRS) for assessment of rooting capacity. Biosyst. Engin. 147, 157-167. doi: 10.1016/j.biosystemseng.2016.06. 003

Millan-Almaraz, J. R., Romero-Troncoso, R. D., Guevara-Gonzalez, R. G., Contreras-Medina, L. M., Carrillo-Serrano, R. V., Osornio-Rios, R. A., et al. (2010). FPGA-based fused smart sensor for real-time plant-transpiration dynamic estimation. Sensors 10, 8316-8331. doi: 10.3390/s100908316

Müller, R., Serek, M., Sisler, E. C., and Andersen, A. S. (1998). Ethylene involvement in leaf abscission, chlorosis, and rooting of Codiaeum variegatum var. pictum (Lodd) Muell 'Aucubaefolia'. Gartenbauwiss 63, 66-71.

Mutui, T. M., Mibus, H., and Serek, M. (2005). Effects of thidiazuron, ethylene, abscisic acid and dark storage on leaf yellowing and rooting of Pelargonium cuttings. J. Hortic. Sci. Biotech. 80, 543-550. doi: 10.1080/14620316.2005. 11511975

Nguyen, T. H. N., Tänzer, S., Rudeck, J., Winkelmann, T., and Debener, T. (2020). Genetic analysis of adventitious root formation in vivo and in vitro in a diversity panel of roses. Sci. Hortic. 266:109277. doi: 10.1016/j.scienta.2020. 109277

Novak, O., Napier, R., and Ljung, K. (2017). Zooming in on plant hormone analysis: tissue- and cell-specific approaches. Ann. Rev. Plant Biol. 68, 323-348. doi: 10.1146/annurev-arplant-042916-040812

Orlikowska, T. (1992). Effect of amino acids on rooting of apple dwarf rootstocks in vitro. Biol. Plant 34, 39-44. doi: 10.1007/bf02925788

Osterc, G., and Stampar, F. (2011). Differences in endo/exogenous auxin profile in cuttings of different physiological ages. J. Plant. Physiol. 168, 2088-2092. doi: 10.1016/j.jplph.2011.06.016

Otiende, M. A., Nyabundi, J. O., Ngamau, K., and Opala, P. (2017). Effects of cutting position of rose rootstock cultivars on rooting and its relationship with mineral nutrient content and endogenous carbohydrates. Sci. Hortic. 225, 204-212. doi: 10.1016/j.scienta.2017.07.009

Peterson, B. J., Sanchez, O., Burnett, S. E., and Hayes, D. J. (2018). Comparison of four systems for propagation of Coleus by stem cuttings. Horttechnology 28, 143-148. doi: 10.21273/Horttech03926-17

Petrasek, J., and Friml, J. (2009). Auxin transport routes in plant development. Development 136, 2675-2688. doi: 10.1242/dev.030353
Poethig, R. S. (2013). Vegetative phase change and shoot maturation in plants. Curr. Top. Dev. Biol. 105, 125-152. doi: 10.1016/B978-0-12-396968-2.00005-1

Rapaka, V. K., Bessler, B., Schreiner, M., and Druege, U. (2005). Interplay between initial carbohydrate availability, current photosynthesis and adventitious root formation in Pelargonium cuttings. Plant Sci. 168, 1547-1560. doi: 10.1016/j. plantsci.2005.02.006

Rapaka, V. K., Faust, J. E., Dole, J. M., and Runkle, E. S. (2007a). Diurnal carbohydrate dynamics affect postharvest ethylene responsiveness in portulaca (Portulaca grandiflora 'Yubi Deep Rose') unrooted cuttings. Postharv. Biol. Technol. 44, 293-299. doi: 10.1016/j.postharvbio.2006.12.004

Rapaka, V. K., Faust, J. E., Dole, J. M., and Runkle, E. S. (2007b). Effect of time of harvest on postharvest leaf abscission in lantana (Lantana camara L. 'Dallas Red') unrooted cuttings. Hortscience 42, 304-308. doi: 10.21273/hortsci.42.2. 304

Rapaka, V. K., Faust, J. E., Dole, J. M., and Runkle, E. S. (2008). Endogenous carbohydrate status affects postharvest ethylene sensitivity in relation to leaf senescence and adventitious root formation in Pelargonium $c$ uttings. Postharv. Biol. Technol. 48, 272-282. doi: 10.1016/j.postharvbio.2007.10.001

Rasmussen, A., Hosseini, S. A., Hajirezaei, M. R., Druege, U., and Geelen, D. (2015). Adventitious rooting declines with the vegetative to reproductive switch and involves a changed auxin homeostasis. J. Exp. Bot. 66, 1437-1452. doi: $10.1093 / j x b / e r u 499$

Riccardi, M., Mele, G., Pulvento, C., Lavini, A., d'Andria, R., and Jacobsen, S. E. (2014). Non-destructive evaluation of chlorophyll content in quinoa and amaranth leaves by simple and multiple regression analysis of RGB image components. Photosynth. Res. 120, 263-272. doi: 10.1007/s11120-0149970-2

Rigon, J. P. G., Capuani, S., Fernandes, D. M., and Guimaraes, T. M. (2016). A novel method for the estimation of soybean chlorophyll content using a smartphone and image analysis. Photosynthetica 54, 559-566. doi: 10.1007/s11099-0160214- $\mathrm{x}$

Roitsch, T., and Gonzalez, M. C. (2004). Function and regulation of plant invertases: sweet sensations. Trends Plant Sci. 9, 606-613. doi: 10.1016/j.tplants. 2004.10.009

Ruedell, C. M., de Almeida, M. R., and Fett-Neto, A. G. (2015). Concerted transcription of auxin and carbohydrate homeostasis-related genes underlies improved adventitious rooting of microcuttings derived from far-red treated Eucalyptus globulus Labill mother plants. Plant Physiol. Biochem. 97, 11-19. doi: 10.1016/j.plaphy.2015.09.005

Rufai, S., Hanafi, M. M., Rafii, M. Y., Mohidin, H., and Omar, S. R. S. (2016). Growth and development of moringa (Moringa oleifera L) stem cuttings as affected by diameter magnitude, growth media, and indole-3-butyric acid. Ann. For. Res. 59, 209-218. doi: 10.15287/afr.2016.686

Sager, M., Yeat, N. C., Pajaro-Van der Stadt, S., Lin, C., Ren, Q. Y., and Lin, J. (2015). Transcriptomics in cancer diagnostics: developments in technology, clinical research and commercialization. Expert Rev. Mol. Diagn. 15, 1589-1603. doi: 10.1586/14737159.2015.1105133

Sanchez, O., Burnett, S. E., and Peterson, B. J. (2020). Environment, photosynthesis, and adventitious rooting of manchurian lilac cuttings propagated in overhead mist, submist, and combination systems. Hortscience 55, 78-82. doi: 10.21273/ Hortsci14473-19

Scheres, B., and van der Putten, W. H. (2017). The plant perceptron connects environment to development. Nature 543, 337-345. doi: 10.1038/nature22010

Schwambach, J., Fadanelli, C., and Fett-Neto, A. G. (2005). Mineral nutrition and adventitious rooting in microcuttings of Eucalyptus globulus. Tree Physiol. 25, 487-494. doi: 10.1093/treephys/25.4.487

Steffens, B., and Rasmussen, A. (2016). The physiology of adventitious roots. Plant Physiol. Biochem. 170, 603-617. doi: 10.1104/pp.15. 01360

Steppe, K. (2015). Contribution of plant sensors to new developments in horticulture. Acta Hortic. 1099, 55-61. doi: 10.17660/actahortic.2015. 1099.2

Takahashi, F., Sato-Nara, K., Kobayashi, K., Suzuki, M., and Suzuki, H. (2003). Sugar-induced adventitious roots in Arabidopsis seedlings. J. Plant Res. 116, 83-91. doi: 10.1007/s10265-002-0074-2

Taylor, B. D., and Hoover, B. K. (2018). Foliar auxin application improves adventitious rooting of wall germander cuttings. Horttechnology 28, 17-21. doi: 10.21273/Horttech03891-17 
Tolentino, M. A. K. P., Albano, D. R. B., and Sevilla, F. B. (2018). Piezoelectric sensor for ethylene based on silver(I)/polymer composite. Sensor Actuat. B Chem. 254, 299-306. doi: 10.1016/j.snb.2017. 07.015

Tombesi, S., Palliotti, A., Poni, S., and Farinelli, D. (2015). Influence of light and shoot development stage on leaf photosynthesis and carbohydrate status during the adventitious root formation in cuttings of Corylus avellana L. Front. Plant Sci. 6:973. doi: 10.3389/fpls.2015.00973

Ueda, H., and Kusaba, M. (2015). Strigolactone regulates leaf senescence in concert with ethylene in Arabidopsis. Plant Physiol. 169, 138-147. doi: 10.1104/pp.15. 00325

van Rongen, M., Bennett, T., Ticchiarelli, F., and Leyser, O. (2019). Connective auxin transport contributes to strigolactone-mediated shoot branching control independent of the transcription factor BRC1. PLoS Genet. 15:e1008023. doi: 10.1371/journal.pgen.1008023

Vergara-Diaz, O., Vatter, T., Kefauver, S. C., Obata, T., Fernie, A. R., and Araus, J. L. (2020). Assessing durum wheat ear and leaf metabolomes in the field through hyperspectral data. Plant J. 102:14636. doi: 10.1111/tpj. 14636

Wilkerson, E. G., Gates, R. S., Zolnier, S., Kester, S. T., and Geneve, R. L. (2005). Predicting rooting stages in poinsettia cuttings using root zone temperaturebased models. J Am. Soc. Hortic. Sci. 130, 302-307. doi: 10.21273/Jashs.130.3. 302

Yanagisawa, S., Yoo, S. D., and Sheen, J. (2003). Differential regulation of EIN3 stability by glucose and ethylene signalling in plants. Nature 425, 521-525. doi: $10.1038 /$ nature 01984

Yang, H. Y., Klopotek, Y., Hajirezaei, M. R., Zerche, S., Franken, P., and Druege, U. (2019). Role of auxin homeostasis and response in nitrogen limitation and dark stimulation of adventitious root formation in petunia cuttings. Ann. Bot. 124, 1053-1066. doi: 10.1093/aob/mcz095

Yasodha, R., Kamala, S., Kumar, S. R. A., Kumar, R. D., and Kalaiarasi, K. (2008). Effect of glucose on in vitro rooting of mature plants of Bambusa nutans. Sci. Hortic. 116, 113-116. doi: 10.1016/j.scienta.2007.10.025
Zerche, S., and Druege, U. (2009). Nitrogen content determines adventitious rooting in Euphorbia pulcherrima under adequate light independently of prerooting carbohydrate depletion of cuttings. Sci. Hortic. 121, 340-347. doi: 10. 1016/j.scienta.2009.02.012

Zerche, S., Haensch, K. T., Druege, U., and Hajirezaei, M. R. (2016). Nitrogen remobilisation facilitates adventitious root formation on reversible darkinduced carbohydrate depletion in Petunia hybrida. BMC Plant Biol. 16:219. doi: 10.1186/s12870-016-0901-6

Zerche, S., Lohr, D., Meinken, E., and Druege, U. (2019). Metabolic nitrogen and carbohydrate pools as potential quality indicators of supply chains for ornamental young plants. Sci. Hortic. 247, 449-462. doi: 10.1016/j.scienta.2018. 12.029

Zhang, G. F., Zhao, F., Chen, Y. Q., Pan, Y., Sun, L. J., Bao, N., et al. (2019). Jasmonate-mediated wound signalling promotes plant regeneration. Nat. Plants 5, 491-497. doi: 10.1038/s41477-019-0408-x

Zhang, W. X., Fan, J. J., Tan, Q. Q., Zhao, M. M., and Cao, F. L. (2017). Mechanisms underlying the regulation of root formation in Malus hupehensis stem cuttings by using exogenous hormones. J. Plant Growth Regul. 36, 174-185. doi: 10.1007/ s00344-016-9628-8

Zhuo, M. N., Sakuraba, Y., and Yanagisawa, S. (2020). A jasmonate-activated MYC2-Dof2.1-MYC2 transcriptional loop promotes leaf senescence in Arabidopsis. Plant Cell 32, 242-262. doi: 10.1105/tpc.19.00297

Conflict of Interest: The author declares that the research was conducted in the absence of any commercial or financial relationships that could be construed as a potential conflict of interest.

Copyright (C) 2020 Druege. This is an open-access article distributed under the terms of the Creative Commons Attribution License (CC BY). The use, distribution or reproduction in other forums is permitted, provided the original author(s) and the copyright owner(s) are credited and that the original publication in this journal is cited, in accordance with accepted academic practice. No use, distribution or reproduction is permitted which does not comply with these terms. 